\title{
The Uncertain Path to Enterprise Architecture (EA) Maturity in the South African Financial Services Sector
}

\author{
Avsharn Bachoo \\ School of Economic and Business Sciences, University of the Witwatersrand (Wits), \\ Johannesburg
}

\begin{abstract}
The research described in this article used the resource-based view (RBV) of the firm as an underlying theoretical framework to explore the relationship between enterprise architecture (EA) maturity and associated business value in the South African financial services environment. EA maturity was examined as an intangible resource and as a source of heterogeneity. The study identified the capabilities of business units at different levels of EA maturity, and found that EA is implemented at a coarse-grain level at lower organisational levels, and at finer-grain levels as one moves up the maturity curve. The study also found that EA is a source of both tangible and intangible forms of business value.

\section{Keywords}

resource-based view (RBV), enterprise architecture (EA), enterprise architecture (EA) maturity, financial services, business value, tangible business value, intangible business value, South Africa

DOI: https://doi.org/10.23962/10539/26110

\section{Recommended citation}

Bachoo, A. (2018). The uncertain path to enterprise architecture (EA) maturity in the South African financial services sector. The African Journal of Information and Communication (AJIC), 21, 97-119. https://doi.org/10.23962/10539/26110
\end{abstract}

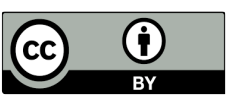

This article is licensed under a Creative Commons Attribution 4.0 International (CC BY 4.0) licence: http://creativecommons.org/licenses/by/4.0 


\section{Introduction}

The business and information technology (IT) ecosystem is in a constant state of change (Santana et al., 2016). Organisations operate in a complex, highly dynamic environment, driven by technological advances, disruptive innovations, regulatory changes, and globalisation (Panetto et al., 2016).The available literature demonstrates rapid acceptance of enterprise architecture (EA) within the major sectors of the economy (Lapalme et al., 2016; Vallerand, Lapalme, \& Moïse, 2017).

Research shows that EA is an instrument that can be used to reduce system complexity (Lankhorst, 2013; Lumor, Chew, \& Gill, 2016); achieve business-IT alignment (Bricknall, Darrell, \& Nilsson, 2006; Pereira \& Sousa, 2005); improve system integration (Boh \& Yellin, 2007; Venkatesh, Bala, Venkatraman, \& Bates, 2007); enhance IT management and strategic competitiveness (Kappelman, 2010); and assist stakeholders to visualise design (Cardwell, 2008). These benefits illustrate the value and growing relevance of EA to organisations.

This article outlines the findings from a study of EA maturity and associated business value in the South African financial services sector. The sections that follow present the study's context and theoretical framing, the research purpose and methodology, the findings, and then a summary and conclusion.

\section{Context and theoretical framing}

How does EA maturity influence business value? This was the question that provided the focus for this study. Limited research has been conducted to explore the relationship between EA capabilities and organisational business value, and there is also minimal research which examines EA as an intangible resource and basis for business value (see Kaisler \& Armour, 2017; Ross et al., 2006; Tamm, Reynolds, Seddon, Framption, \& Shanks, 2015). Furthermore, available EA maturity studies (see Alwadain, Fielt, Korthaus, \& Rosemann, 2014; Tamm et al., 2015; Vallerand et al., 2017) have not specifically focused on the way that EA affects business value outcomes at different maturity levels. These gaps are further compounded by inconsistencies in the definition (see Cronk \& Fitzgerald, 1999) of the term "business value", as organisations use different definitions and have multiple interpretations of value (see Keyes-Pearce, 2005).

Investigating these matters is important in order for organisations to be able to understand the forms of business value that can be attained as they progress towards higher levels of EA maturity. Specifically, the aim of this research was to understand the connection between the EA practices of an organisation and the business value associated with those EA practices in the South African financial services environment. 
The dynamic capabilities and resource-based view (RBV) frameworks were both considered for possible suitability to this study. Dynamic capabilities theory (Douma \& Schreuder, 2013; Ludwig \& Pemberton, 2011) takes an "outside in" (Teece, Pisano, \& Shuen, 1997, p. 526) perspective, and focuses on an organisation's ability to "reconfigure resources" (Bowman \& Ambrosini, 2010, p. 30) in order to address rapidly changing environments and industry forces (Teece et al., 1997). However, the dynamic capabilities framework has been criticised as not having a sufficiently clear, broadly accepted definition (Williamson, 2016); as lacking theoretical foundations; and as having poor empirical support (Easterby-Smith, Lyles, \& Peteraf, 2009; Williamson, 2016)—as well as containing a complex and disconnected body of research (Barreto, 2009).

RBV (Barney, 1991; Rothaermel, 2015; Wernerfelt, 1984) takes an "inside out" perspective (Madhani, 2009, p. 4) and focuses on an organisation's creation, development, and choice of internal resources to create business value (Connor, 2002; Ludwig \& Pemberton, 2011). This perspective seeks to give organisations the ability to innovate and envisage products that "customers need but have not yet even imagined" (Prahalad \& Hamel, 1990, p. 6). RBV was selected as the underlying theoretical framework for this study because of its support of the research objectives, i.e., because RBV helps explain the ways in which EA capabilities can influence value for an organisation (Amit \& Schoemaker, 1993; Seddon, 2014).

RBV states that organisations should look inside their environments for tangible and intangible sources of value (Barney, 1991; Rothaermel, 2015; Wernerfelt, 1984). Tangible resources are physical assets that are a source of short-term value and can be easily purchased in the open market (Barney, 1991; Schöenherr, 2009). Intangible resources have no physical presence, cannot be easily purchased, and are the primary source of long-term business value (Wade \& Hulland, 2004). Heterogeneity assumes that intangible resources of organisations differ from each other and provide longterm business value (Barney, 1991; Patas, Bartenschlager, \& Goeken, 2012). This study examined EA as an intangible resource (Ross et al., 2006; Tamm et al., 2015), and examined the maturity of EA as a source of heterogeneity (Anderson \& Eshima, 2013; López, 2005). Understanding these elements is important because competitors cannot easily imitate intangible resources, due to their tendency towards heterogeneity (Barney, 1991; Rothaermel, 2015). It must be noted, however, that RBV has been criticised by some due to its arguably tautological definitions, and problems with its operationalisation (Priem \& Butler, 2001; Williamson, 1999).

The quality management maturity grid (QMMG) (Crosby, 1979), stages of growth (Nolan, 1979), and capability maturity model integration (CMMI) (Paulk, Curtis, Chrissis, \& Weber, 1993), were also assessed as possible suitable reference models for this study. CMMI is one of the most widely accepted and established models, in both academia and industry, for assessing the capability maturity of an 
organisation (Fendt, 2013). Importantly, CMMI is used as a blueprint to derive other maturity models (Van Steenbergen, Schipper, Bos, \& Brinkkemper, 2010), including the architecture capability maturity model (ACMM) (De Carvalho et al., 2016a, 2016b). ACMM was selected as the maturity model reference for this study, as it identifies levels of maturity and contains appropriate mechanismscomprising processes, communication, business IT alignment, senior-management involvement, and finance- that were relevant to this study's aim to evaluate EA capabilities. Furthermore, the model describes five levels of maturity. During the first level of maturity, labelled initial, EA practices are ad hoc and inconsistent. During the second level of maturity, called repeatable, EA practices are simple. At the third level, called defined, EA is characterised by standard business practices. At the fourth level, labelled managed, EA practices are quantitatively managed with metrics. At the fifth level, called optimised, there are proactive EA practices (De Carvalho et al., 2016a; 2016b).

Examination of literature on the term "business value" revealed a wide range of views (see, for example, Chesbrough, 2012). Some contend that business value definitions are "unclear, frequently inadequate, often partisan and sometimes completely absent" (Bannister \& Remenyi, 2000, p. 43). It has been argued that there is a "lack of construct validity, and definitional inconsistency" in the definitions of business value (Cronk and Fitzgerald, 1999, p. 406).

This study used the definition of business value provided by the RBV framework, whereby the term includes both tangible resources that are a source of short-term value and intangible resources that are a source of long-term value (Dyer, Singh, \& Hesterly, 2018).

\section{Research purpose and methodology}

The research approached EA and EA maturity as phenomena having both tangible and intangible features (Ross et al., 2006; Tamm et al., 2015), and EA maturity as a source of value-creating heterogeneity (Anderson \& Eshima, 2013; López, 2005), from an RBV perspective. The study sought to contribute to the RBV theory by examining EA maturity as a basis for the generation of both tangible and intangible business value (Ross et al., 2006; Tamm et al., 2015).

Furthermore, this research viewed EA in terms of granularities of refinement (Harrison, 2013). Coarse-grain refinement assesses EA from a conceptual perspective, in terms of business needs, objectives, goals, relationships and capabilities. The medium-grain refinement assesses EA from a logical perspective, in terms of how the conceptual view will be achieved. Finally, the fine-grain refinement assesses EA from a physical perspective, in terms of where the logical processes are implemented (Emery \& Hilliard, 2009; Stuht \& Speck, 2016). 
The available literature (see Bui, 2012; Tamm et al., 2015; Vallerand et al., 2017; Wang \& Zhao, 2009) does not show the granularities of EA refinement utilised at the different levels of maturity. Different EA granularities of refinement could influence business value differently at the various levels of EA maturity, and organisations can benefit from information on where to appropriately focus EA effort (Schekkerman, 2011).

The study used qualitative data-gathering methods, consisting of individual interviews and examination of document artefacts, all within a short timeframe. This provided the rich data necessary to deeply understand the constructs of EA maturity and business value within a time-bounded scope (Saint-Germain, 2016).

The South African financial services sector was selected as a setting for this study due to its strong regulatory, compliance, risk, and legal frameworks (Fosu, 2013; Luiz \& Charalambous, 2009). The study collected data from business units in three South African banks: a total of nine business units of different sizes, complexities and maturity levels. Using a purposive sampling approach, a total of 28 individuals, all business and IT professionals, were interviewed across the nine units. Document artefacts were additionally analysed (Collis \& Hussey, 2013), such as requirement documents (functionality specifications), architectural diagrams (software blueprints), design diagrams, and technical specifications.

Thematic analysis was used to analyse the data, search for patterns, and reveal themes (Braun \& Clarke, 2006; Terry, Hayfield, Clarke, \& Braun, 2017). Synchronic and inter-judge reliability criteria, as well as instrument, internal and construct validity criteria, were used (Miles, Huberman, \& Saldana, 2014; Yin, 2013). Synchronic reliability-i.e., the consistency of outcomes observed from multiple sources within a similar period - was achieved for this study by using a standardised interview protocol and artefact form (Baskerville \& Myers, 2015; Yin, 2013). These instruments were used for multiple participants and documents, after which similar patterns were investigated. Furthermore, I sought to achieve inter-judge reliabilityi.e., identifying consistencies in observations by multiple observers-through the presentation of results, and discussions with participants, at conferences (DeVellis, 2003).

Triangulation of the interview data from different participants contributed to the internal validity of this research (Bisman, 2010; Denzin \& Lincoln, 2011), and the document artefacts were collected to provide further insights into the responses from the interviews (Denzin \& Lincoln, 2011). It must be noted that this study only focused on understanding and explaining a specific case-study environment (Dobson, Myles, \& Jackson, 2007), as opposed to a focus on producing transferable and universally generalisable findings (Archer, Bhaskar, Lawson, \& Norrie, 2013; Bhaskar, 2015). 


\section{Findings on business units' EA maturity characteristics}

This section consolidates and presents the findings from the nine business units assessed in this research. (The Appendix contains the interview questions used.) The thematic analysis findings on EA maturity characteristics are mapped in Figure 1, against four levels of EA maturity - with the names assigned to each level (initial, repeatable, defined, managed) taken from the ACMM framework outlined above:

- EA maturity level 1: initial

- EA maturity level 2: repeatable

- EA maturity level 3: defined

- EA maturity level 4: managed

None of the nine business units assessed was found to exhibit the characteristics of EA maturity level 5: optimised.

Figure 1: Business units' EA maturity characteristics

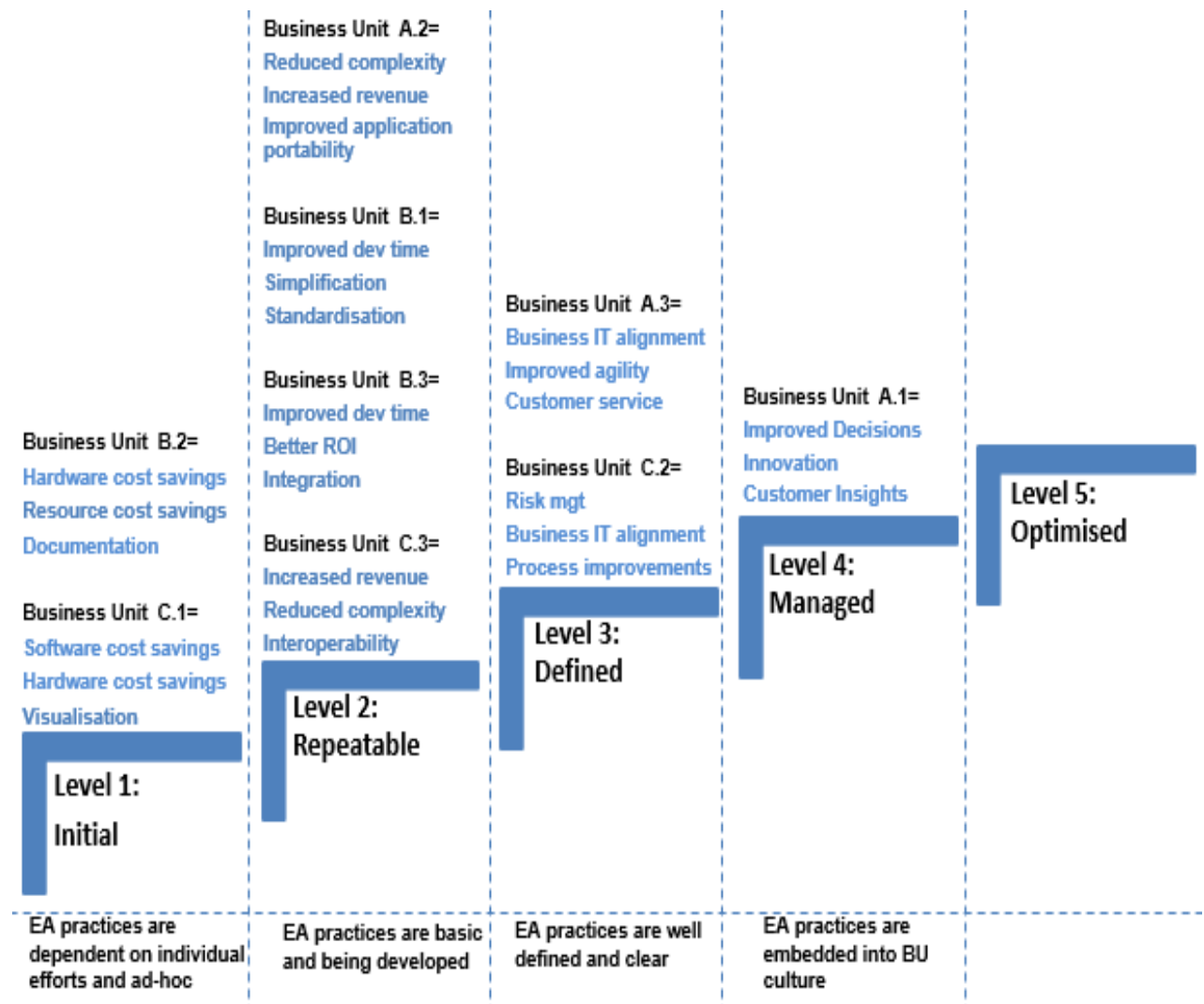




\section{EA maturity level 1 characteristics}

In Bank B, Business Unit 2 (B.2 in Figure 1), the thematic analysis identified the following theme: informal EA capabilities and practices are new and still gaining momentum. EA practices within this business unit were found to be inconsistent as they were dependent on specific staff members who advocated EA's value for particular projects. Furthermore, this business unit was characterised by an excessively high staff turnover rate, which resulted in only intermittent EA momentum. An inconsistent degree of management support, and internal conflict, featured within this business unit, with some managers advocating EA practices while others had no interest such activities.

This business unit defined its overall EA at a coarse granularity of refinement, as it focused on EA objectives and strategic goals without defining the ways in which these objectives and goals were to be executed. This business unit specified where its technology was physically deployed, and depicted the layers and environments developed with an open systems interconnection (OSI) reference model. Forms of value, such as improved documentation, were experienced. EA created a common platform and single view of initiatives for senior management. This helped manage stakeholder expectations and enabled consensus to be reached on matters of disagreement. Furthermore, EA influenced resource efficiencies which improved return on investment for the business unit. This led to hardware and software savings.

In Bank C, Business Unit 1 (C.1 in Figure 1), the following theme was identified: $E A$ practices dependent on individual person efforts. The research found that this business unit had informal EA practices and capabilities that were dependent on specific staff. EA was implemented at a business unit level, as opposed to an organisational level, and was not linked to the bank's overall strategy. Basic EA practices evolved organically, with some management involvement. A committed budget for EA was available.

This business unit's environment was disorganised, with EA reliant on particular champions. However, these champions were often moved to projects that were in crisis, and EA expertise and knowledge left when these individuals were reassigned.

Similar to what was found at Bank B, Business Unit 2 (B.2), this business unit defined its overall EA at a coarse granularity of refinement without defining the ways in which EA objectives and goals were to be executed. This business unit specified the technology required to support its operations, which was comprised of a vendor-neutral architecture with a solution focus on simplicity that facilitated problem-solving. EA was found to be enabling rationalisation of applications, the reuse of technologies, and correct selection of technologies-resulting in software and hardware cost savings. Furthermore, EA blueprints enabled visualisation of systems by management. 


\section{EA maturity level 2 characteristics}

In Bank A, Business Unit 2 (A.2 in Figure 1), the thematic analysis identified the following: simple $E A$ capabilities evident with basic EA practices being developed. It was found that essential communication took place for all projects. There were formal design processes with, however, a few gaps prevalent. Furthermore, there was no future-state architecture in place. There was a shortage of skills, and a reliance on a few experts to execute initiatives. It was found that more management involvement was required to prevent project silos. Furthermore, this business unit was characterised by selective degrees of commitment from the senior managers.

This business unit defined its overall EA at a coarse granularity of refinement, as it focused on EA objectives and strategic goals without defining the ways in which these objectives and strategies were to be executed. Forms of value such as reduced complexity were experienced. EA enabled the business unit to generate a strategic view of its activities, characterised by a holistic view of its customer and a clearly structured approach to problem-solving. EA helped the unit convert complex technical details into simple business language that was easy for management to understand and agree on. Furthermore, EA enabled the business unit to visualise the impact of financial decisions, which helped the unit experience a quicker return on its investments and, in turn, increased revenue. Finally, the business unit experienced an improvement in the portability of its applications due to the influence of EA.

In Bank B, Business Unit 1 (B.1 in Figure 1), the thematic analysis identified: $E A$ in progress, with basic $E A$ processes recently introduced and being formalised. The use of EA was found to be resulting in simple business-IT alignment that was being experienced at a management level. However, more convincing was required on the use of EA to gain momentum, as it was not being fully leveraged by management. Senior management involvement with EA practices was erratic, with a mixed understanding of EA value. This business unit did have a few clear EA communication and governance standards that were documented within their repository. However, the communications occurred infrequently. Furthermore, there was only intermittent EA input into the finance strategy within this business unit.

This business unit had documentation available for its core and "as is" systems, but secondary and "to be" systems were still to be concluded. It was found that an EA repository has been developed, but navigation within this repository was difficult for staff. This business unit defined its overall EA at a coarse granularity of refinement, focused on EA objectives and strategic goals. Improved development time, simplification, and standardisation were identified as value experienced within the unit.

In Bank B, Business Unit 3 (B.3 in Figure 1), the theme determined was: $E A$ being established as well as EA processes being developed and communicated. Basic EA 
processes and up-to-date documentation were in place for critical core systems, and were stored within an EA repository. EA was found to be emerging as fundamental to business operations and useful for understanding regulations, with regular staff awareness activities taking place. Business-IT alignment was steadily progressing. Financial benefits such as risk reduction were experienced. There was gradually increasing involvement by senior managers in EA practices, but with varying degrees of commitment, with some managers advocating EA and other resisting or opposing any new practices. Additionally, there were staff problems in the unit with regard to focusing on EA, due to work overload. A dependency on specific individuals, as well as a skills gap, were problems.

EA was found to be enabling faster development time for building systems within the business unit. This business unit defined its overall EA at a coarse granularity of refinement, focused on EA objectives and strategic goals. The technology domain comprised a blueprint that depicted the configurations, servers, networks, vision, and strategy of the business unit. The EA repository facilitated reusability, resulting in faster system development and less integration complexity across systems in the bank. An improved return on investment had been achieved due to the faster deployment of systems.

In Bank C, Business Unit 3 (C.3 in Figure 1), the following theme was identified: $E A$ capabilities that are new and being set up with current-state-environment complete. EA practices were being set up and the current-state-environment blueprints were complete. A technical reference model was being developed for EA. However, this model was not linked to the future target EA state. This business unit had built a shared folder to store its EA reference models, with EA communications taking place, but sporadically. A new management team, which supported EA, had recently been appointed, but there was some resistance, characterised by elements of internal politics.

Efficiency benefits, a small amount of business-IT alignment value, and financial benefits such as rationalisation and redundancy were being experienced. This business unit had a few EA finance standards were documented in the EA repository, but there was no formal finance strategy with regard to EA within the unit. The unit defined its overall EA at a coarse granularity of refinement, but had sought to specify some the ways in which the technology objectives were to be achieved by drawing up a collaborative framework that incorporated a strategic roadmap for interactions with business stakeholders. The roadmap further defined the locations of the deployment environments. Increased revenue, reduced complexity, and interoperability, were found to be as forms of value experienced because of EA. 


\section{EA maturity level 3 characteristics}

In Bank A, Business Unit 3 (A.3 in Figure 1), the theme identified was: formal $E A$ capabilities as well as comprehensive EA processes supported by management, with current and future states integrated into the systems development life cycle (SDLC). There was found to be good management support for EA, coupled with strong businessIT alignment, allowed innovation and growth within this business unit. Senior management, including the CEO of the unit, actively supported and embraced EA practices. Furthermore, unit staff understood the benefit of EA and actively contributed to architectural initiatives. This unit had comprehensively documented governance processes of all its EA components.

This unit further included EA when making all financial decisions, and complied with EA standards when procuring any IT equipment, making use of a specialised EA tool. The unit defined its overall EA at a medium granularity of refinement, as it focused on the ways in which EA was executed by specifying its business, application, data, and technology domain processes from a logical perspective oriented towards how the conceptual view was to be achieved. Its technology domain artefact detailed a cloud technology stack incorporating software and infrastructure as a service model. The design included hardware, servers, and the network layout. Business-IT alignment was being experienced, as EA created a common platform for management to align strategies and to become more agile and responsive to change. Improved agility and improved customer were forms of value experienced by the unit.

In Bank C, Business Unit 2 (C.2 in Figure 1), the thematic finding was: comprehensive EA capabilities and practices that are clear and regularly communicated to all staff. This business unit had comprehensively documented its EA governance processes, future state architecture, EA standards, and reference models, and it had formed an EA architecture board. Furthermore, resource prioritisation was experienced, with strong business-IT alignment and a focus on business solutions. Senior management commitment to EA practices was experienced within the unit. Communication was prevalent, with the CIO providing frequent EA feedback to staff through emails. Furthermore, the unit's EA plans were linked to both the business unit and the bank's strategic and tactical plans. The document artefacts showed that this business unit had incorporated EA in its financial processes. The business unit had also procured an expert EA toolset.

This unit defined its overall EA at a medium granularity of refinement, as it focused on the ways in which EA was executed, specifying the domain processes. The technology comprised a model that depicted the current plumbing and served as a predictor to see the effects of changes, incorporating inputs, tools, and outputs. The business unit made use of reference models as a base, customisable for various segments. EA was found to be helping senior management mitigate risk by improving project selection, i.e., helping management make informed design choices 
before systems were built. Efficiencies, such as improved processing times, were key forms of value being experienced through EA.

\section{EA maturity level 4 characteristics}

In Bank A, Business Unit 1 (A.1 in Figure 1), the theme established was: entrenched, comprehensive and updated EA business practices that are well-established and part of the business unit culture. This business unit distributed regular communications to its staff on the latest EA architecture developments and standards. Its EA practices were continuously advanced by management. The unit had built strong internal skills by sponsoring and encouraging EA training for staff. The unit recognised EA as a professional career with formal roles and responsibilities. The unit had further developed a defined formal path for architects to progress in their careers. A key differentiator at this level was that this business unit had specific metrics to evaluate its EA practices.

The business unit had predictive financial models that were available in the EA repository. Furthermore, senior management were proactively involved with the architecture board, and the unit's finance department reviewed EA before any major purchases. This unit defined its overall EA at a fine granularity of refinement, as it focused on where the physical implementation of EA was taking place. This business unit's technology domain artefacts described where the technology was physically deployed. The technology was designed as a hybrid, cloud-layered micro-services architecture that was stateless and resided in a container environment. Improved decision-making, innovation, and customer insights were forms of value being experienced as a result of EA.

\section{EA maturity level 5}

The EA practices within ACMM at level 5 (optimised) are characterised in the literature as being predictive and in a state of continuous improvement (De Carvalho, Rocha, \& de Vasconcelos, 2016; Paulk, Curtis, Chrissis, \& Weber, 2001). None of the business units assessed in this study were found to feature elements of level 5 maturity.

\section{Findings on business units' inputs and outputs at levels of EA maturity}

As stated earlier, this study sought to examine EA as an intangible resource input (Boh \& Yellin, 2007; Ross et al., 2006; Tamm et al., 2015) and maturity as a source of heterogeneity (Anderson \& Eshima, 2013; López, 2005). The study further examined forms of business value as outputs. Figure 2 illustrates how the RBV framework helps reveal the ways in which organisations transform their inputs into outputs (Amit \& Schoemaker, 1993; Dutta, Narasimhan, \& Rajiv, 2005). 
Figure 2: Business unit inputs and outputs at levels of EA maturity

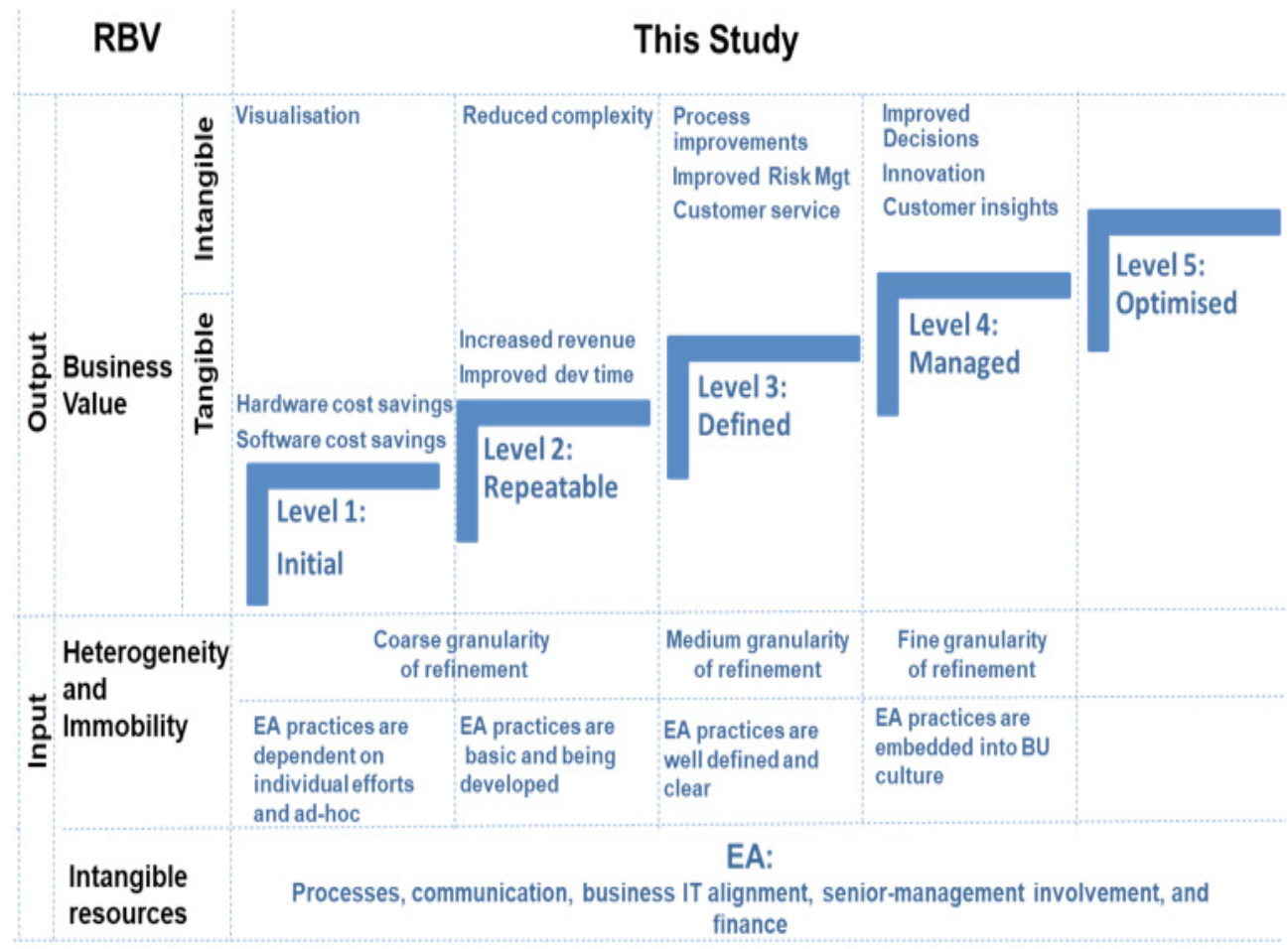

\section{Level 1 inputs and outputs}

This research found that at level 1 maturity, EA practices were characterised as ad hoc, with no unified practices across the various EA domains, largely due to a dependency on specific individuals. EA documentation was a combination of highand low-quality artefacts. The two business units at this level (B.2, C.1) perceived EA as a tool for the technology department to "draw diagrams" (B.2, interviewee 5) and document their systems. Moreover, there was minimal involvement of senior management with EA. To quote a research interviewee, "it's up to the architecture team to make a success of the situation" (C.1, interviewee 4).

However, it was found that even units taking advantage of EA on an ad hoc basis had the potential to experience immediate value. Tangible outcomes such as hardware and software cost savings are achieved through reuse of technologies, the correct selection of technologies, and improved documentation. Intangible outcomes, such as visualisation of systems, are attained through EA blueprints that help to horizontally view aspects of business and IT landscapes, and to improve procurement decisions by rationalisation of systems and licences. 
A participant in one of the units at this EA maturity level stated that the unit reviewed its EA catalogue prior to large technology purchases. Previously, there had been three different reporting applications, two sales systems, and two bespoke customer relationship systems that performed similar functions within the bank. According to this participant, "we had a patchwork of independent systems [...] architecture helped identify and eliminate these duplications [...] this reduced IT spending across the group" (C.1, interviewee 4).

\section{Level 2 inputs and outputs}

The largest number of business units-four (A.2, B.1, B.3, C.3) out of the nine studied-fell within maturity level 2. Participant interviews a notably reduced dependency on specific individuals in comparison to level 1. These business units had simple blueprints as well as standards and principles for their current EA states. However, no evidence was found of future or target state architectures. It was found there was alignment between the business and technology departments at this level of maturity, as the technologies were mapped to the business objectives. According to one interviewee:

[Our EA] is still fairly new, with a few holes missing, but still captures this department's structure in a formal design that supports our evolution and change $[\ldots]$ it also ensures that our technical designs align to the bank's business strategic objectives. (A.2, interviewee 1)

However, business units at this level still perceived EA as a tool for the technology department, and EA still did not prominently feature within these business units' strategic agendas. There was found to be only selective involvement in EA by senior management, with varying degrees of commitment. According to one interviewee:

The management team [has] agreed to get more involved with the architectural process [...]. We will see how this evolves as it was only recently agreed and there is still internal squabbling amongst them. However, they all realise that architecture plays a key role in aligning our systems to meet customer needs. (A.2, interviewee 3).

Improved development time, a tangible outcome experienced by business units at this level, was found to be achieved via an EA repository of reusable components containing standard interfaces that reduced integration complexity. Intangible outcomes such as reduced complexity were also attained. According to one interviewee:

Complexities began to emerge as the technologies began to overlap each other [...]. We faced the problem of buying new technologies without decommissioning legacy systems [...]. We eventually ended up with a tangle of overlapping new and old systems that no one really understands, 
and costs us money. Our architecture endeavours have played a role in reducing and managing the complexity chaos for us. (C.3, interviewee 3)

\section{Level 3 inputs and outputs}

The EA practices were found to be more structured within business units from level 3 onwards. The business units at this level (A3, C2) had simple EA practices in place that were well-accepted and communicated to the teams. They used EA processes to measure and share outcomes of projects with the staff. These outcomes were further used in post-implementation reviews and staff performance reviews. EA documentation at this level was comprehensive and, importantly, contained future target environments for the unit.

Business units at this level were found to be incorporating their EA practices into strategic planning, by creating a link between EA and key projects. According to one interviewee, "the architecture practices are entrenched into the project prioritisation forums, [and] can't be treated as a separate function" (C.2, interviewee 1). This linkage was found to be essentially forcing formal engagement between the unit's IT and business departments.

The C.2 business unit was found to be utilising financial metrics such as return on investment, net present value, and cost-benefit analysis; customer metrics such as customer satisfaction surveys, call-centre-holding time, and problem-resolution time; process metrics such as measuring task times; and compliance metrics such as compliance frameworks. A C.2 interviewee stated: "I see our architecture as the plumbing of the business [...]. It details the inputs, tools, and outputs" (C.2, interviewee 1). It was found at this level that EA aided business units with process improvements by helping them to visualise and understand complex interconnections between processes that were confusing or conflicting.

Another intangible form of value found at this level was improved risk management. The business units at this level cited the stringent legislative regulations within the sector, as well as frequent amendments to these regulations, and said that EA was found to create value by addressing various risk regulations in a holistic manner across departments in a unit. Improved customer service was another intangible outcome that started to become prominent at this level. The units studied at this level found EA beneficial in mapping their customers' journey across individual departments, with EA helping to facilitate collaboration via sharing customer experiences and identifying service problems that emerged at the handoff points between the departmental silos.

\section{Level 4 inputs and outputs}

The one business unit (A.1) at maturity level 4 viewed EA as a practice that involved applying a set of tools and techniques to solve business problems. EA was entrenched 
into the business decision-making process. To quote one interviewee, "EA [is] integrated into our strategy and core business activities" (A.1, interviewee 4).

This business unit was using metrics such as Delphi techniques, frequency analysis, and percentages of reuse of common designs, which specifically measured aspects of EA. (However, one of the unit's challenges was the inconsistent use of these measures.)

This unit kept its EA documentation updated by reflecting the latest architectures in their production environments. Senior management was actively involved with EA reviews and enhancements. To quote another interviewee, "Manco [the management committee] are part of the architecture review board” (A.1, interviewee 1).

Blueprints and diagrams generated from EA assisted the business unit to visualise and identify patterns in data that subsequently helped it make better decisions. EA enabled innovation by assisting with the rapid implementation of new ideas, and it assisted the unit to understand the potential impact of changes brought about by innovations. A key intangible outcome was found to be enhanced customer insights. According to one interviewee:

a few years ago, a customer walked into a branch and took out a personal loan [and] we did a credit check, and the transaction was simply processed [...]. These days, it goes beyond that transaction [...]. We look at things such as Tweets and Facebook comments to check for any cross-sale opportunities [...].The key is offering the right product at the right place and at the right time, tailored for that specific customer (A.1, interviewee 3).

EA was enabling the business unit to create tailored offerings of products that directly targeted customer-specific needs. EA structures were further helping the unit to gain insights by connecting disparate data silos to create a single, integrated view of a customer.

\section{Summary and conclusion}

The literature survey for this study established that business value in the form of reduced system complexity is attainable from EA (Lapalme et al., 2016; Rouhani, Mahrin, Nikpay, \& Nikfard, 2013). This study found that reduced system complexity was only achievable for organisations operating from EA maturity level 2 onwards.

The literature review also established that business value in the form of improved system integration and standardisation is attainable from EA (Boh \& Yellin, 2007; Venkatesh et al., 2007). The findings of this study concur with the literature, establishing that this form of value was attainable for the business units from level 2 maturities onwards. 
It was also established via the literature review that efficient IT management, leading to reduced solution delivery time and development costs, is a form of value generated by EA (Bernard, 2012; Kappelman, McLean, Johnson, \& Torres, 2016). The findings of this study concur with the literature, finding that this forms of value was attainable across the units, even at level 1 maturity.

The literature review also established that some works position business-IT alignment as achievable from EA (Bricknall et al., 2006; Pereira \& Sousa, 2005). This study findings of this study place more emphasis on business-IT alignment as a source of value, rather than as an outcome, through connecting business and technology components through common threads (see Harrison, 2013; Kurniawan \& Suhardi, 2013).

We also saw that it is argued in some of the literature that EA creates long-term value but minimal short-term value (Bricknall et al., 2006; Van Der Raadt \& Van Vliet, 2009). And the RBV theoretical framework used for this study argues that tangible resources are a source of short-term value, and intangible resources are a source of a long-term value (Barney, 1991). This study identified both tangible and intangible forms of value obtainable from EA, implying that EA is a source of both short-term and long term-value.

Key specific findings were as follows:

Champions: EA champions were found to be influential in helping business units move up the maturity curve. These champions were found to be collaborating with business stakeholders and positioning EA as a joint business-IT venture.

Standardised technologies: Business units across level 1 and 2 maturities had large, diversified portfolios of programming languages, technology infrastructure, and toolsets. This was in contrast to business units at levels 3 and 4, which had implemented standard programming languages and consistent technology infrastructure stacks across a variety of applications. They were using standardised, off-the-shelf packaged technologies within minimal or no customisation. This use of standardised technologies prevented future interface complexity.

Skills: The availability of skilled resources was found to be a major challenge to EA success. Furthermore, business units at lower levels of maturity did not recognise and fully acknowledge EA as a formal career. Conversely, business units at levels 3 and 4 had acknowledged this career path, and had built strong internal skills by sponsoring and encouraging EA training, had recognised EA as a professional career path with formal roles and responsibilities, and had positioned architects at high levels of seniority with substantial decision-making power. 
$\boldsymbol{E A}$ as a practice: The business units at lower maturity levels perceived EA as a blueprint, and as primarily a set of technology decisions. In contrast, the business unit at level 4 maturity viewed EA as a practice, involving application of a set of tools and techniques to solve business problems. Furthermore, this business unit at level 4 had structured EA to target critical business projects, ensuring that EA remained visible and relevant to the business unit through its association with the benefits created by the critical projects. This is a lesson for lower-maturity-level business units wanting to gain momentum in their EA efforts.

Metrics: The study found that business units from maturity levels 1 to 3 utilised financial metrics, customer metrics, process metrics, and compliance metrics. The differentiator at level 4 was the use of statistical metrics specifically designed to measure EA. The level 4 business unit used Delphi techniques to enhance EA decision-making, and frequency analysis to determine patterns for EA improvement.

Customer insights: Customer insights were found to be a sought-after type of value identified by the business units studied. All the business units aspired to achieve this form of value, as it would allow them to understand customer behaviour and subsequently create personalised sales and service offerings. However, it was found that only the unit at level 4 maturity had consolidated its individual databases from the various systems into a single integrated data warehouse providing the ability to search for patterns and proactively present offers to customers based on their behaviours. This architecture contrasted with business units at lower levels of maturity that had different databases for each function. Business units at lower EA maturity levels were experiencing many missed opportunities due to not having a single consolidated view of customer behaviour.

Refinement of EA granularity: This study found a refinement in the granularity of EA as business units moved up the maturity curve. Business units across levels 1 and 2 maturities applied EA at a coarse granularity of refinement, with a focus on defining EA domain objectives and goals. At level 3 maturity, a medium granularity of refinement emerged. At this level, in addition to defining the domain objectives and goals, the units defined the ways in which the objectives were achieved, and specified the application software, particular technologies, and data types and views. The business unit with level 4 maturity defined EA at an even finer granularity of refinement, containing details such as where the physical implementation was taking place and the roles of stakeholders performing the tasks.

In conclusion, this study's findings concur with the argument made 15 years ago by Carr (2003) in the controversial, but still relevant, article entitled "IT Doesn't Matter", which suggested that the only way to get value from IT is to build it into the business. Although EA is not the panacea or "silver bullet" (Brooks, 1987, p. 10) to all issues associated with achieving value, it is definitely a vital piece to the 
puzzle. A core finding presented in existing literature is that organisations that adopt EA obtain value, even on an ad hoc basis (Ross et al., 2006; Tamm et al., 2015). This study has sought to add nuance to that finding, by looking at how EA capabilities evolve at different levels of maturity, and at the types of short-term and long-term value attainable.

\section{References}

Alwadain,A.,Fielt,E.B., Korthaus,A.C., \& Rosemann,M.(2014).A critical realist perspective of enterprise architecture evolution: Conditioning and outcomes. Australasian Journal of Information Systems, 18(3), 213-226. https://doi.org/10.3127/ajis.v18i3.1102

Amit, R., \& Schoemaker, P. J. H. (1993). Strategic assets and organizational rent. Strategic Management Journal, 14(1), 33-46. https://doi.org/10.1002/smj.4250140105

Anderson, B. S., \& Eshima, Y. (2013). The influence of firm age and intangible resources on the relationship between entrepreneurial orientation and firm growth among Japanese SMEs. Journal of Business Venturing, 28(3), 413-429.

https://doi.org/10.1016/j.jbusvent.2011.10.001

Barney,J. (1991). Firm resources and sustained competitive advantage. Journal of Management, 17(1), 99-120. https://doi.org/10.1177/014920639101700108

Barreto,I.(2009). Dynamic capabilities: A review of past research and an agenda for the future. Journal of Management, 36(1), 256-280. https://doi.org/10.1177/0149206309350776

Baskerville, R. L., \& Myers, M. D. (2015). Design ethnography in information systems. Information Systems Journal, 25(1), 23-46. https://doi.org/10.1111/isj.12055

Bernard, S. (2012). An introduction to enterprise architecture, 3rd ed. Bloomington, IN: AuthorHouse.

Bhaskar, R. (2015). A realist theory of science. London: Routledge. https://doi.org/10.4324/9780203090732

Bisman, J. (2010). Postpositivism and accounting research: A (personal) primer on critical realism. Australasian Accounting Business E Finance Journal, 4(4), 3-25.

Boh, W. F., \& Yellin, D. (2007). Using enterprise architecture standards in managing information technology. Journal of Management Information Systems, 23(3), 163-207. https://doi.org/10.2753/mis0742-1222230307

Bowman, C., \&Ambrosini, V. (2010). How value is created, captured and destroyed. European Business Review, 22(5), 479-495. https://doi.org/10.1108/09555341011068903

Bradley, R. V., Pratt, R. M. E., Byrd, T. A., Outlay, C. N., \& Wynn, D. E. (2012). Enterprise architecture, IT effectiveness and the mediating role of IT alignment in US hospitals. Information Systems Journal, 22(2), 97-127. https://doi.org/10.1111/j.1365-2575.2011.00379.x

Braun, V., \& Clarke, V. (2006). Using thematic analysis in psychology. Qualitative Research in Psychology, 3(2), 77-101. https://doi.org/10.1191/1478088706qp063oa

Bricknall, R., Darrell, G., \& Nilsson, H. (2006). Enterprise architecture: Critical factors affecting modelling and management. In ECIS (Ed.), 14th European Conference of Information Systems (ECIS 2006) (pp. 1-13).

Brooks, F. (1987). No silver bullet: Essence and accidents of software engineering. Computer, 20(4), 10-19. https://doi.org/10.1109/mc.1987.1663532 
Bui, Q. N. (2012). Making connections: A typological theory on enterprise architecture features and organizational outcomes. In AMCIS (Ed.), Eighteenth Americas Conference on Information Systems (pp. 1-9).

Cardwell, G. (2008). The influence of enterprise architecture and process hierarchies on company success. Total Quality Management E Business Excellence, 19(1-2), 47-55. https://doi.org/10.1080/14783360701601959

Chesbrough, H. W. (2012). Open innovation: Where we've been and where we're going. Research-Technology Management, 55(August), 20-27. https://doi.org/10.5437/08956308x5504085

Collis, J., \& Hussey, R. (2013). Business Research. Nature, 142, 410-411. https://doi.org/10.1038/142410a0

Connor, T. (2002). The resource-based view of strategy and its value to practising managers. Strategic Change: Briefings in Entrepreneurial Finance, 11(6), 307-316. https://doi.org/10.1002/jsc.593

Cronk, M. C., \& Fitzgerald, E. P. (1999). Understanding "IS business value": Derivation of dimensions. Logistics Information Management, 12(1/2), 40-49. https://doi.org/10.1108/09576059910256240

Crosby, P. B. (1979). Quality is free: The art of making quality certain. New York: New American Library.

De Carvalho,J.V., Rocha,Á., \& Abreu,A. (2016). Maturity models of healthcare information systems and technologies: A literature review. Journal of Medical Systems, 40(6), 1-10. https://doi.org/10.1007/s10916-016-0486-5

De Carvalho, J. V., Rocha, Á., \& De Vasconcelos, J. B. (2016). Maturity models for hospital information systems management: Are they mature? Innovation in Medicine and Healthcare, 2015, 541-552. https://doi.org/10.1007/978-3-319-23024-5 49

Denzin, N. K., \& Lincoln, Y. S. (Eds.). (2011). The SAGE handbook of qualitative research. Thousand Oaks, CA: Sage. https://doi.org/10.1108/13522750910948815

DeVellis, R. F. (2003). Scale development: Theory and applications. 2nd ed. Thousand Oaks, CA: Sage.

Douma, S. W., \& Schreuder, H. (2013). Economic approaches to organizations. New York: Prentice Hall.

Dutta, S., Narasimhan, O.M., \& Rajiv, S. (2005). Conceptualizing and measuring capabilities: Methodology and empirical application. Strategic Management Journal, 26(3), 277-285. https://doi.org/10.1002/smj.442

Dyer, J. H., Singh, H., \& Hesterly, W. S. (2018). The relational view revisited: A dynamic perspective on value creation and value capture. Strategic Management Journal, 39(12), 3140-3162. https://doi.org/10.1002/smj.2785

Easterby-Smith, M., Lyles, M. A., \& Peteraf, M. A. (2009). Dynamic capabilities: Current debates and future directions. British Journal of Management, 20(SUPP. 1), S1-S8. https://doi.org/10.1111/j.1467-8551.2008.00609.x

Emery,D.,\&Hilliard, R.(2009).Every architecture description needs a framework: Expressing architecture frameworks using ISO/IEC 42010. In WICSA/ECSA (Ed.), 2009 Joint Working IEEE/IFIP Conference on Software Architecture and European Conference on Software Architecture (pp. 31-40). https://doi.org/10.1109/wicsa.2009.5290789

Fendt, J. (2013). CEOs and popular management concepts: Innovation heuristics, boundary capability and effectuation. Academy of Management Proceedings, 2013(1).

https://doi.org/10.5465/ambpp.2013.260 
Fosu, S. (2013). Banking competition in Africa: Subregional comparative studies. Emerging Markets Review, 15, 233-254. https://doi.org/10.1016/j.ememar.2013.02.001

Harrison, R. (2013). TOGAF 9 foundation study guide. Berkshire, UK: The Open Group.

Kaisler, S. H., \& Armour, F. (2017). 15 years of enterprise architecting at HICSS: Revisiting the critical problems. In HICSS (Ed.), Proceedings of the 50th Hawaii International Conference on System Sciences (pp. 4807-4816). https://doi.org/10.24251/hicss.2017.585

Kappelman, L. A. (2010). The SIM guide to enterprise architecture. Boca Raton, FL: CRC Press. https://doi.org/10.1201/9781439811146

Kappelman, L. A., McLean, E., Johnson, V., \& Torres, R. (2016). The 2015 SIM IT issues and trends study. MIS Quarterly Executive, 15(1), 55-83.

Keyes-Pearce, S. V. (2005). IT value management in leading firms: The fit between theory and practice. Doctoral dissertation, University of Sydney.

Khaiata, M., \& Zualkernan, I. A. (2009). A simple instrument to measure IT-business alignment maturity. Information Systems Management, 26(2), 138-152.

https://doi.org/10.1080/10580530902797524

Kurniawan, N. B., \& Suhardi. (2013). Enterprise architecture design for ensuring strategic business IT alignment (integrating SAMM with TOGAF 9.1). In IEEE (Ed.), Proceedings of the 2013 Joint International Conference on Rural Information and Communication Technology and Electric-Vehicle Technology, rICT and ICeV-T. https://doi.org/10.1109/rict-icevt.2013.6741505

Lankhorst, M. (2013). Enterprise architecture at work: Modelling, communication and analysis. In J. L. G. Dietz, E. Proper, \& J. Tribolet (Eds.), The enterprise engineering series, Vol. 27. Berlin: Springer. https://doi.org/10.1007/978-3-642-29651-2

Lapalme, J., Gerber, A., Van Der Merwe, A., Zachman, J., Vries, M. De, \& Hinkelmann, K. (2016). Exploring the future of enterprise architecture: A Zachman perspective. Computers in Industry, 79, 103-113. https://doi.org/10.1016/j.compind.2015.06.010

López, S. V. (2005). Competitive advantage and strategy formulation: The key role of dynamic capabilities. Management Decision, 43, 661-669. https://doi.org/10.1108/00251740510597699

Ludwig, G., \& Pemberton, J. (2011). A managerial perspective of dynamic capabilities in emerging markets: The case of the Russian steel industry. Journal for East European Management Studies, 16(3), 215-236. https://doi.org/10.5771/0949-6181-2011-3-215

Luiz, J. M., \& Charalambous, H. (2009). Factors influencing foreign direct investment of South African financial services firms in Sub-Saharan Africa. International Business Review, 18(3), 305-317. https://doi.org/10.1016/j.ibusrev.2009.02.008

Lumor, T., Chew, E., \& Gill, A. Q. (2016). Exploring the role of enterprise architecture in IS-enabled Ot: An EA principles perspective. In IEEE (Ed.), Enterprise Distributed Object Computing Workshop (EDOCW) (pp. 1 -6). https://doi.org/10.1109/edocw.2016.7584360

Madhani, P. M. (2009). Resource based view (RBV) of competitive advantages: Importance, issues and implications. Indian Management Research Journal, 1(2), 1-15.

Miles, M. B., Huberman, A. M., \& Saldana, J. (2014). Qualitative data analysis: A methods sourcebook. Thousand Oaks, CA: Sage. https://doi.org/10.2307/1163741

Nolan, R. L. (1979). Managing the crises in data processing. Harvard Business Review, 57(March), 115-127. 
Panetto, H., Zdravkovic, M., Jardim-Goncalves, R., Romero, D., Cecil, J., \& Mezgár, I. (2016). New perspectives for the future interoperable enterprise systems. Computers in Industry, 79(C), 47-63. https://doi.org/10.1016/j.compind.2015.08.001

Patas,J., Bartenschlager,J., \& Goeken, M.(2012). Resource-based view in empirical it business value research--an evidence-based literature review. 2012 45th Hawaii International Conference on System Sciences, 5062-5071. https://doi.org/10.1109/hicss.2012.503

Paulk, M. C., Curtis, B., Chrissis, M. B., \& Weber, C. V. (1993). Capability maturity model, version 1.1. IEEE Software, 10(4), 18-27. https://doi.org/10.1109/52.219617

Paulk, M. C., Curtis, B., Chrissis, M. B., \& Weber, C. V. (2001). Capability maturity model for software. In R. H. Thayer (Ed.), Software engineering project management (2nd ed.) (pp. 48-59). Los Alamitos, CA: IEEE Computer Society Press.

Pereira, C. M., \& Sousa, P. (2005, March). Enterprise architecture: Business and IT alignment. In Proceedings of the 2005 ACM Symposium on Applied Computing (pp. 13441345). https://doi.org/10.1145/1066677.1066980

Prahalad, C. K., \& Hamel, G. (1990). Strategic intent. Harvard Business Review, 67(3), 6376.

Priem, R.L., \& Butler,J. E. (2001). Tautology in the resource-based view and the implications of externally determined resource value: Further comments. Academy of Management Review, 26(1), 57-66. https://doi.org/10.5465/amr.2001.4011946

Ross, J. W., Weill, P., \& Robertson, D. (2006). Enterprise architecture as strategy: Creating a foundation for business execution. Cambridge, MA: Harvard Business Press.

Rothaermel, F. T. (2015). Strategic management: Concepts and cases. New York: McGraw-Hill Irwin.

Rouhani, B. D., Mahrin, M. N., Nikpay, F., Ahmad, R. B., \& Nikfard, P. (2015). A systematic literature review on enterprise architecture implementation methodologies. Information and Software Technology, 62, 1-20. https://doi.org/10.1016/j.infsof.2015.01.012

Rouhani, B. D., Mahrin, M. N., Nikpay, F., \& Nikfard, P. (2013). A comparison enterprise architecture implementation methodologies. In IEEE (Ed.), Proceedings - 2013 International Conference on Informatics and Creative Multimedia (pp. 1-6). https://doi.org/10.1109/icicm.2013.9

Saint-Germain, M. A. (2016). Pre-experimental designs for research. Retrieved from http:// web.csulb.edu/ msaintg/ppa696/696preex.htm\#Cross-Sectional Design

Santana, A., Fischbach, K., \& Moura, H. (2016, January). Enterprise architecture analysis and network thinking: A literature review. In Hawaii International Conference on System Sciences (HICSS) (Ed.), 2016 49th Hawaii International Conference on System Sciences (pp. 4566-4575). https://doi.org/10.1109/hicss.2016.567

Saunders, M. L., Lewis, P., \& Thornhill, A. (2016). Research methods for business students. London: Financial Times.

Schekkerman,J. (2011). Enterprise Architecture Tool Selection Guide. Institute for Enterprise Architecture Developments. Trafford.

Schöenherr M. (2009) Towards a common terminology in the discipline of enterprise architecture. In G. Feuerlicht, \& W. Lamersdorf (Eds.), Service-oriented computing - ICSOC 2008 Workshops. ICSOC 2008. Lecture Notes in Computer Science, Vol. 5472. Berlin: Springer. https://doi.org/10.1007/978-3-642-01247-1 40

Seddon, P. B. (2014). Implications for strategic IS research of the resource-based theory of the firm: A reflection. The Journal of Strategic Information Systems, 23(4), 257-269. https://doi.org/10.1016/j.jsis.2014.11.001 
Silverman, D. (2013). Doing qualitative research: A practical handbook. London: Sage.

Stuht, T., \& Speck, A. (2016). Bridging the gap between independent enterprise architecture domain models. In W. Abramowicz, R. Alt, \& B. Franczyk (Eds.), Business Information Systems (BIS 2016): Lecture Notes in Business Information Processing, Vol. 255 (pp. 277288). Cham, Switzerland: Springer. https://doi.org/10.1007/978-3-319-39426-8 22

Tamm, T., Reynolds, P., Seddon, P. B., Framption, K. M., \& Shanks, G. (2015). How an Australian retailer enabled business transformation through enterprise architecture. MIS Quarterly Executive, 14(4), 181-193.

Teece, D. J., Pisano, G., \& Shuen, A. (1997). Dynamic capabilities and strategic management. Strategic Management Journal, 18(3), 509-533.

https://doi.org/10.1002/(sici)1097-0266(199708)18:7<509::aid-smj882>3.0.co;2-z

Terry, G., Hayfield, N., Clarke, V., \& Braun, V. (2017). Thematic analysis. In C. Willig, \&W.

Stainton Rogers (Eds.), The SAGE Handbook of Qualitative Research in Psychology, 17-35. http://dx.doi.org/10.4135/9781526405555.n2

Vallerand, J., Lapalme, J., \& Moïse, A. (2017). Analysing enterprise architecture maturity models: A learning perspective. Enterprise Information Systems, 11(6), 859-883. https://doi.org/10.1080/17517575.2015.1091951

Van der Raadt, B., \& Van Vliet, H. (2009). Assessing the efficiency of the enterprise architecture function. In Working Conference on Practice-Driven Research on Enterprise Transformation (pp. 63-83). Springer, Berlin, Heidelberg. https://doi.org/10.1007/978-3-642-01859-6 5

Van Steenbergen M., Schipper, J., Bos, R., \& Brinkkemper, S. (2010). The dynamic architecture maturity matrix: Instrument analysis and refinement. In A. Dan, F. Gittler, \& Toumani F. (Eds.), ICSOC/ServiceWave 2009, Lecture Notes in Computer Science (LNCS), Volume 6275 (pp. 48-61). https://doi.org/10.1007/978-3-642-16132-2 5

Venkatesh, V., Bala, H., Venkatraman, S., \& Bates, J. (2007). Enterprise architecture maturity: The story of the Veterans Health Administration. MIS Quarterly Executive, 6(2), 79-90.

Wade, M., \& Hulland, J. (2004). The resource-based view and information systems research: Review, extension, and suggestions for future research. MIS Quarterly, 28(1), 107-142. https://doi.org/10.2307/25148626

Wang, X., \& Zhao, Y. (2009, August). An enterprise architecture development method in Chinese manufacturing industry. In IEEE (Ed.), 2009 Ninth International Conference on Hybrid Intelligent Systems (pp. 226-230), 12-14 August, Shenyang, China. https://doi.org/10.1109/his.2009.260

Wernerfelt, B. (1984). A resource-based view of the firm. Strategic Management Journal, 5, 171-180. https://doi.org/10.1002/smj.4250050207

Williamson, O. E. (1999). Strategy research: Governance and competence perspectives. Strategic Management Journal, 20(12), 1087-1108. https://doi.org/10.1002/(sici)1097-0266(199912)20:12<1087::aid-smj71>3.3.co;2-q

Williamson, P. (2016). Building and leveraging dynamic capabilities: Insights from accelerated innovation in China. Global Strategy Journal, 6(3), 197-210. https://doi.org/10.1002/gsj.1124

Yin, R. K. (2013). Case study research: Design and methods. Thousand Oaks, CA: Sage. 


\section{Appendix: Interview questions}

1. In what way have your business unit's EA processes been established?

2. In what way do these EA processes bring value to your department?

3. In what way has the progression of your business unit's EA been communicated?

4. In what way does EA communication help you to bring value to your department?

5. In what way has introducing EA influenced business-IT alignment in your business unit?

6. In what way does EA bring value in terms of achieving business and IT alignment?

7. In what way are the senior managers of your business unit involved in the establishment and ongoing development of EA?

8. In what way does EA bring value to senior managers in your business unit?

9. In what way has introducing EA influenced your finance strategy?

10. In what way does EA bring value to finance in your department? 